\title{
Spatial and Temporal Distribution of Zooplankton Communities of Coastal Marine Waters Receiving Different Human Activities (Fish and Pearl Oyster Farmings)
}

\author{
Kwang-Hyeon Chang ${ }^{*}, 1$, Hideyuki Doi ${ }^{2}$, Yuichiro Nishibe ${ }^{3}$, Yumiko Obayashi ${ }^{1}$, Shin-ichi Nakano ${ }^{4}$ \\ ${ }^{1}$ Center for Marine Environmental Studies, Ehime University, Bunkyo-cho 2-5, Matsuyama 790-8577, Japan \\ ${ }^{2}$ Institute for Chemistry and Biology of the Marine Environment, Carl-von-Ossietzky University Oldenburg, \\ Schleusenstrasse 1 D-26382 Wilhelmshaven, Germany \\ ${ }^{3}$ Ocean Research Institute, The University of Tokyo, 1-15-1 Minamidai, Nakano-ku, Tokyo 164-8639, Japan \\ ${ }^{4}$ Center for Ecological Research, Kyoto University, Hirano 2-509-3, Otsu, 520-2113, Japan
}

\begin{abstract}
Seasonal changes of zooplankton communities were monitored at two coastal marine areas, Uchiumi and Fukuura Bays located at the Uwa Sea, east side of Bungo Channel. The two sites are close to each other (c.a. $20 \mathrm{~km})$ with similar habitat environments, but receive different environmental stresses from aquaculture activities, pearl oyster farming for Uchiumi Bay and fish farming for Fukuura Bay. Since both bays have no inflowing river and small populations in the catchment, the impacts of different aquaculture activities on meso- and microzooplankton communities were compared. As results, Fukuura Bay showed higher ammonium and phosphate concentrations, suggesting that fish farming could accelerate eutrophication more seriously. The dominant species of mesozooplankton were similar at the two sampling sites with dominance of small coastal calanoid copepod, Paracalanus spp., but the abundances of larger calanoid species, Calanidae, Eucalanidae, Temoridae and Acartiidae, were markedly higher in Uchiumi Bay. Small cyclopoid copepods, Oithona spp. were abundant at both sites, but the densities varied seasonally, and often more abundant at Fukuura Bay. The abundances of microzooplankton including rotifers and small Oithona copepodids were higher at Fukuura Bay. Results suggest that fish farms accompanying discharge of nutrients from additional food supply for fish may seriously modify zooplankton community structure by decreasing the abundance of mesozooplankton through accelerating the eutrophication of coastal waters.
\end{abstract}

\section{INTRODUCTION}

Eutrophication due to the loading of excessive nutrients by human activities is one major environmental problem in estuarine and coastal waters $[1,2]$. Land flux, including human waste, fertilizer and livestock waste from the catchment area has been considered as the most important nutrient loading to coastal area [3]. However, addition to this terrestrial-base nutrient loading, mariculture has been also described as a potential source of eutrophication in the coastal areas, as crop amount of aquaculture increases and accounts for ca. one-quarter of total fisheries catch [4].

Fish and pearl farms are typical aquaculture types in Japan, and they are densely distributed in Japanese coastal waters [5]. Their presence often induces the increase of nutrients concentration in the water column through the discharge of large amounts of organic waste (unconsumed fish food, fecal, pseudofecal and excretory matter), and they also accumulate in the underlying sediment and affect the sediment chemistry. However, due to the difference in the level of organic input between fish and pearl cultures, their impacts on coastal environments and biota are different [5].

*Address correspondence to this author at the Center for Marine Environmental Studies, Ehime University, Bunkyo-cho 2-5, Matsuyama 790-8577, Japan; Tel: (81) 899469773; Fax: (81) 899469773;

E-mail: changkwang38@hotmail.com
Such farming impacts have been extensively investigated focusing on the responses of phytoplankton biomass and macrobenthos with nutrients dynamics and chemistry [5-8]. However, limited information is available about the effects of farming activities on coastal marine zooplankton communities. Since the main aquaculture for local fisheries often shifts from one to the other depending on market economy and demand for fisheries products, it is necessary to compare and estimate the impacts of two types of aquacultures on coastal ecosystem.

Zooplankton plays a central role in the coastal marine food web. At the same time, the structure and function of species composition are highly susceptible to induce environmental changes, especially eutrophication [9]. It is suggested that replacement of zooplankton species composition by eutrophication results in changes in the food chain structure and acceleration of biogenic materials from embayments to outer ocean. Therefore, the investigation of temporal and spatial dynamics of zooplankton community is important for the estimation of aquaculture impacts on coastal ecosystem as well as farm management.

In the present study, in order to assess and compare the impacts of farming activities on coastal zooplankton communities, we studied seasonal changes of zooplankton community at two coastal marine waters, Uchiumi and Fukuura Bays, neighboring but receiving different farming 

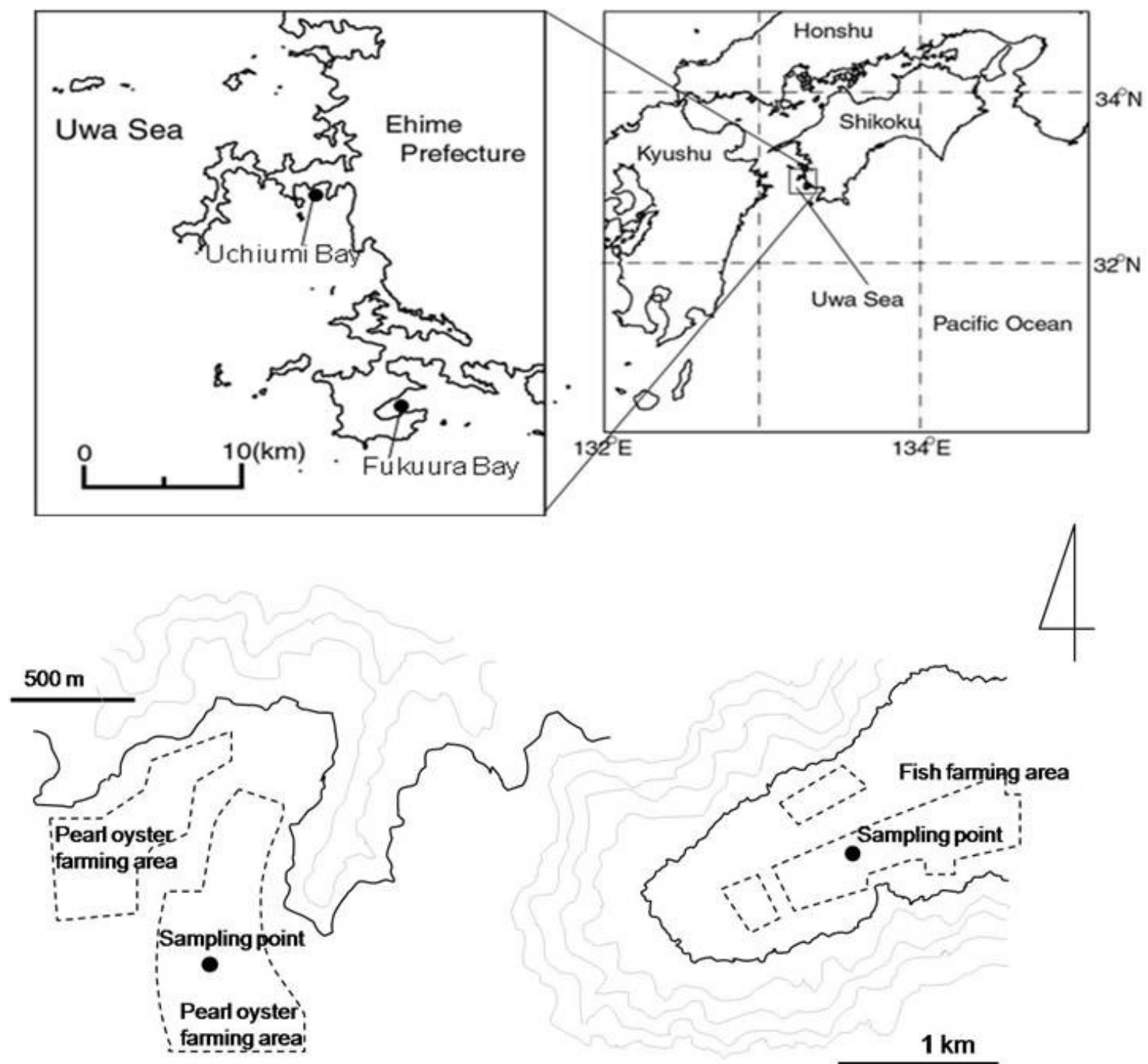

\section{Uchiumi Bay}

Fig. (1). Map of study sites.

effects (pearl oyster and fish farmings) at the Uwa Sea, east side of the Bungo Channel.

\section{MATERIALS AND METHODS}

Uchiumi $\left(33^{\circ} 02^{\prime} \mathrm{N}, 132^{\circ} 28^{\prime} \mathrm{E}\right)$ and Fukuura $\left(32^{\circ} 55^{\prime}\right.$ $\mathrm{N}, 132^{\circ} 30^{\prime}$ E) Bays are located at the Uwa Sea, southwest of Ehime Prefecture, Japan (Fig. 1). Aquaculture has been the key industry supporting the local economy for several decades. Pearl oyster (Pinctada fucata martensii) cultivation is extensively conducted at Uchiumi Bay while fish farming (yellow tail and sea bream) is major aquaculture at Fukuura Bay. Maximum water depths of sampling points are ca. $50 \mathrm{~m}$ at Uchiumi and $35 \mathrm{~m}$ at Fukuura Bay. Both sampling sites are approximately $1 \mathrm{~km}$ away from the shore, and there are no inflowing streams in both bays.

Samplings were conducted monthly from May 2005 to May 2006. Water temperature and salinity were measured vertically using a Chlorotech profiler (Areck Electronics Co., ACL-208-KD). The water samples were taken using 61 VanDorn sampler (at the depths of $0,2,5,10,20,30,40 \mathrm{~m}$ at Uchiumi Bay and 0, 5, 10, 20,30 $\mathrm{m}$ at Fukuura Bay), and collected water was used for measuring nutrient concentrations and phytoplankton biomass (Chl. a). Nutrient concentrations were measured using Autoanalyzer (BRAN+LUEBEE, Traacs 800). By size-fractionated filtering using the fine mesh net, Chl. $a$ concentrations were categorized into $<2 \mu \mathrm{m}$ (pico), 2-20 $\mu \mathrm{m}$ (nano), and total (without filtering) Chl. $a$ concentrations. The treated water samples were filtered by Nuclepore filters, and chl. $a$ was extracted by preserving the filter in $\mathrm{N}, \mathrm{N}$-dimethylformamide (DMF). The Chl. $a$ concentrations were determined using a fluorometer (Turner Designs, 10-AU). The statistical tests of measured environmental variables between the bays (Wilcoxon rank sum test) were performed using the software $\mathrm{R}$ version 2.6.1 (The $\mathrm{R}$ Foundation for Statistical Computing, Vienna, Austria).

Mesozooplankton were collected with vertical net towing from the depth $45 \mathrm{~m}$ (Uchiumi) and $35 \mathrm{~m}$ (Fukuura) to surface using the plankton net $(200 \mu \mathrm{m}$ mesh). Microzooplankton samples (6 1) were collected with VanDorn sampler at $5-10 \mathrm{~m}$ depth intervals from surface to bottom, and then filtered with $40 \mu \mathrm{m}$ mesh net. Filtered 
samples were fixed with neutralized formalin (final concentration 1-4\%). The biomass of calanoid copepods was calculated with the equation of length-weight relationships [10]. The similarity of calanoid copepods composition for each season and site was examined using Bray Curtis as a measure of similarity (based on nontransformed biomass data), and nonmetric multidimensional scaling (MDS) plot was created using PRIMER version 5.2.9 (PRIMER-E, Plymouth). The diversity index (Shannon's $\mathrm{H}^{\prime}$ ) of calanoid copepods was calculated based on their biomass also using PRIMER version 5.2.9.

\section{RESULTS}

As summarized at Table 1, the two sampling sites Uchiumi Bay and Fukuura Bay, showed similar water temperature and salinity levels (Table 1). Although annual mean phytoplankton biomass (chl. a) showed no significant differences between the bays because of seasonal fluctuations, higher biomass of total and nano-sized phytoplankton were observed at Fukuura Bay during spring and summer. Annual mean values of nutrient concentrations were clearly higher at Fukuura Bay with higher concentrations of ammonium and phosphate.

At both sites, mesozooplankton showed high abundances from spring to summer, reaching densities of more than 1,000 ind. $\mathrm{m}^{-3}$, but the densities decreased and maintained low until winter (Fig. 2). However, the density of calanoid copepods was markedly higher at Uchiumi Bay. On the contrary, for cyclopoid copepods, mainly Oithona spp. that have smaller body sizes than calanoid copepods, the higher densities were often observed at Fukuura Bay, although there were seasonal fluctuations. They showed different seasonal succession patterns from those of calanoid copepods. Both Oncaea spp. and Corycaeus spp. showed higher densities in Uchiumi but with high seasonal variations.
Table 1. Average ( \pm Standard Error) Water Temperature, Salinity, Phytoplankton Biomass and Nutrient Concentrations During the Study Period. Vertical Average Values of All Sampling Depths were Used for the Calculations of Average $(*, P<0.005$ in Wilcoxon Rank Sum Test)

\begin{tabular}{|c|c|c|}
\hline & Uchiumi Bay & Fukuura Bay \\
\hline Water temperature $\left({ }^{\circ} \mathrm{C}\right)$ & $19.42 \pm 2.82$ & $20.52 \pm 3.96$ \\
\hline Salinity & $34.29 \pm 0.21$ & $34.25 \pm 0.42$ \\
\hline \multicolumn{3}{|l|}{$\begin{array}{l}\text { Phytoplankton biomass } \\
\quad\left(\text { Chl. } a, \mu \mathrm{g} \mathrm{L}^{-1}\right)\end{array}$} \\
\hline Total Chl. $a$ & $1.71 \pm 0.67$ & $3.28 \pm 2.48$ \\
\hline Nano-sized Chl. $a$ & $0.96 \pm 0.25$ & $1.56 \pm 1.32$ \\
\hline Pico-sized Chl. $a$ & $0.48 \pm 0.13$ & $0.35 \pm 0.18$ \\
\hline \multicolumn{3}{|l|}{$\begin{array}{l}\text { Nutrients concentrations } \\
\qquad\left(\mu \mathrm{M} \mathrm{L} \mathrm{L}^{-1}\right)\end{array}$} \\
\hline Nitrite $\left(\mathrm{NO}_{2}-\mathrm{N}\right)$ & $1.31 \pm 1.27$ & $1.37 \pm 1.38$ \\
\hline Nitrate $\left(\mathrm{NO}_{3}-\mathrm{N}\right)$ & $0.96 \pm 0.94$ & $0.96 \pm 1.01$ \\
\hline Ammonium $\left(\mathrm{NH}_{4}-\mathrm{N}\right)^{*}$ & $1.26 \pm 0.78$ & $5.64 \pm 1.88$ \\
\hline Phosphorus $\left(\mathrm{PO}_{4}-\mathrm{P}\right)^{*}$ & $0.22 \pm 0.08$ & $0.61 \pm 0.23$ \\
\hline Silica (Si) & $5.67 \pm 1.65$ & $4.39 \pm 2.05$ \\
\hline
\end{tabular}

Considering the biomass, calanoid copepods absolutely dominate the copepod abundance throughout a year. Although the small body sized genus, Paracalanus spp. were dominant in both bays, the biomass and composition of calanoid communities were different between the sites with almost three times higher biomass at Uchiumi Bay (Fig. 3). They were numerically dominant, and their biomass also occupied more than $50 \%$ of annual mean copepods biomass
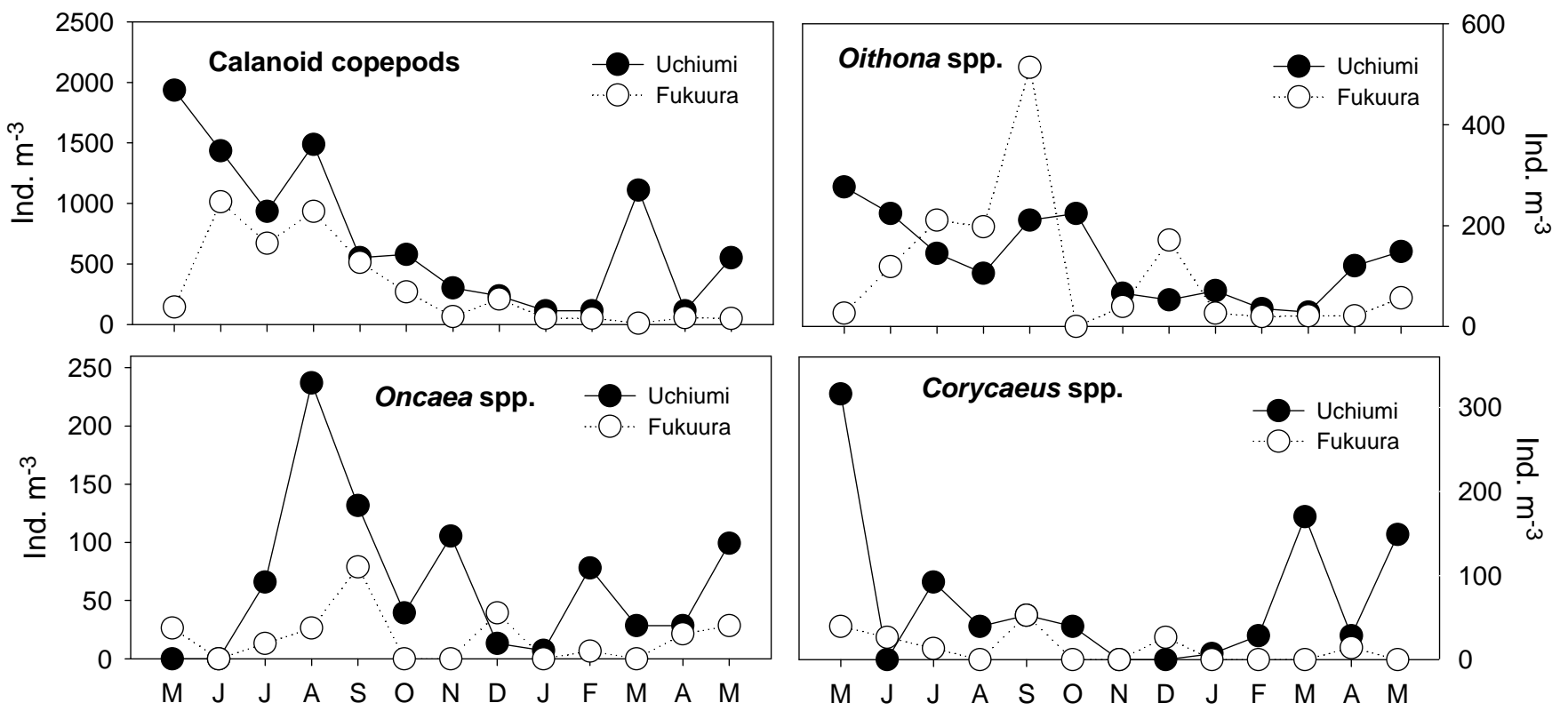

Fig. (2). Seasonal changes in abundance of mesozooplankton, calanoid copepods, cyclopoid copepods (Oithona spp.), Oncaea spp., and Corycaeus spp. at Uchiumi and Fukuura Bays during the study period (May 2005-May 2006). 
at Uchiumi Bay and more than $80 \%$ at Fukuura Bay. Even though recorded copepod genus throughout the study period were similar in both bays with the dominance of Paracalanus app., Temora turbinata and Acartia spp., their species composition patterns were quite different. One distinct difference was the contribution of large species biomass to that of total copepods. Large calanoid copepods including Calanus spp. and Eucalanus spp. are often abundant at Uchiumi Bay, but they were rarely found at Fukuura Bay. In Fukuura Bay, both Paracalanus spp. and Temora turbinata extremely dominated copepod community throughout the study period. The MDS plot of two sites and all sampling times combined shows that their compositions were similar only during summer (June - July) and winter (January and February) (Fig. 4). Consequently, the diversity of calanoid copepod community was markedly lower at Fukuura Bay throughout the year (Fig. 5).

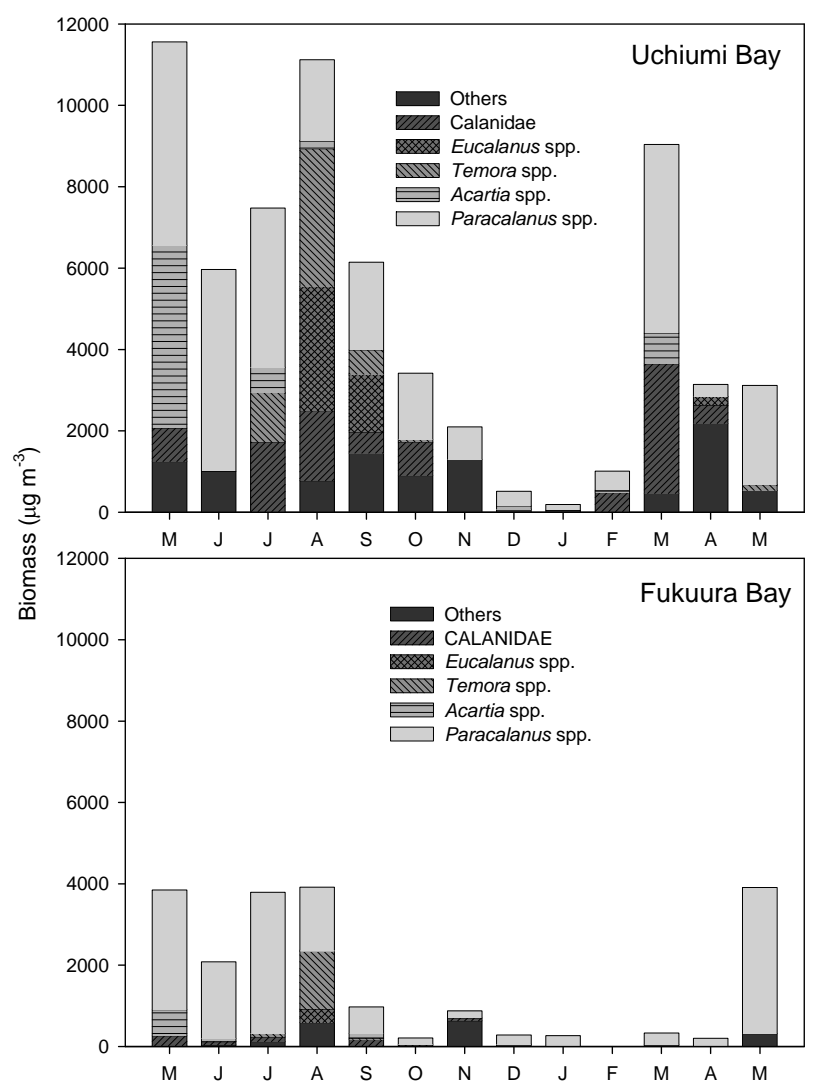

Fig. (3). Seasonal changes in biomass of calanoid copepods at Uchiumi and Fukuura Bays during the study period (May 2005May 2006).

Different from mesozooplankton, the densities of microzooplankton were apparently higher at Fukuura Bay with markedly higher rotifer densities (Fig. 6). The density of Synchaeta sp. and Philodium sp. near surface in Fukuura Bay reached densities of more than 100 ind. $1^{-1}$ in early summer, while their density at Uchiumi Bay was less than 5 ind. $1^{-1}$. However, in both bays, rotifers were rarely found in other seasons. Barnacle larvae showed different temporal and spatial pattern between the bays. No vertically heterogeneous distributions of Oithona copepodids $(<200$

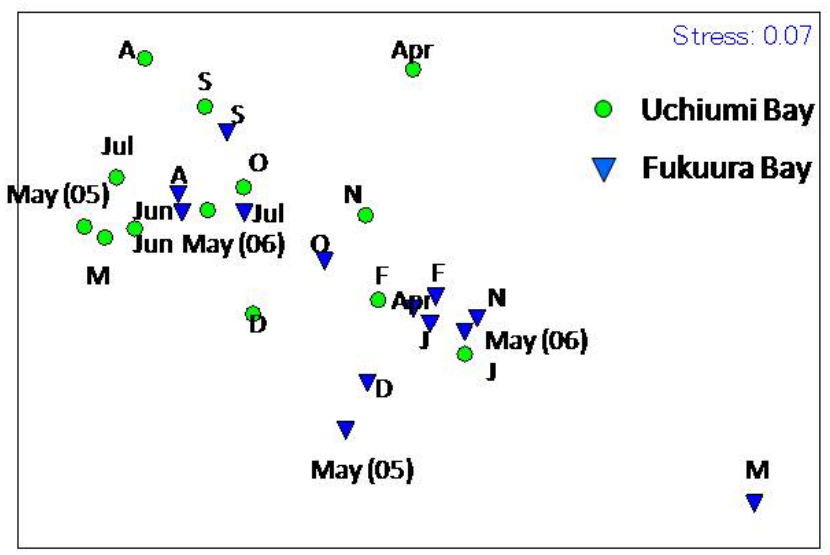

Fig. (4). Multidimensional scaling (MDS) plot showing seasonally different composition of calanoid copepods in Uchiumi and Fukuura Bays.

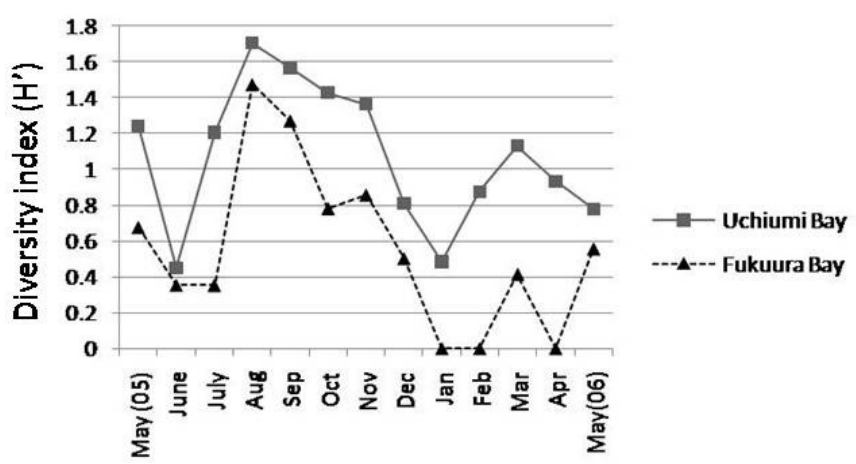

Fig. (5). Comparison of seasonal changes in Diversity Index (H) of calanoid copepods community at Uchiumi and Fukuura Bays during the study period (May 2005-May2006).

$\mu \mathrm{m}$ in body size) were observed in two bays with higher abundance in Fukuura Bay. However, copepod nauplius showed seasonally different vertical distribution patterns in the two bays. In Fukuura, nauplius densely aggregated near the bottom during summer, but showed vertically homogeneous distribution in other seasons. In Uchiumi Bay, the aggregation of nauplius in deeper layer was observed in early spring, March.

\section{DISCUSSION}

Both bays are located at Bungo Channel in southwestern Japan, where an intermittent physical event, 'Kyu-cho', frequently occurs [11]. It brings warm oligotrophic water to the coast and affects the water temperature. The physical and chemical impact of this event seems to be similar at both bays [12]. Since there is no inflowing river and small populations dwell in the surrounding area, farming activity can be one major factor affecting the water quality of the bays.

It is known that higher amount of organic matters produced in fish farming induces larger impact on the surrounding environments than other types of aquacultures [5]. More eutrophicated environments and consequent high phytoplankton biomass in Fukuura Bay, therefore, can be attributed to extensive fish farming activities in this area. It has been known that $60 \%$ of the organic carbon of the input 


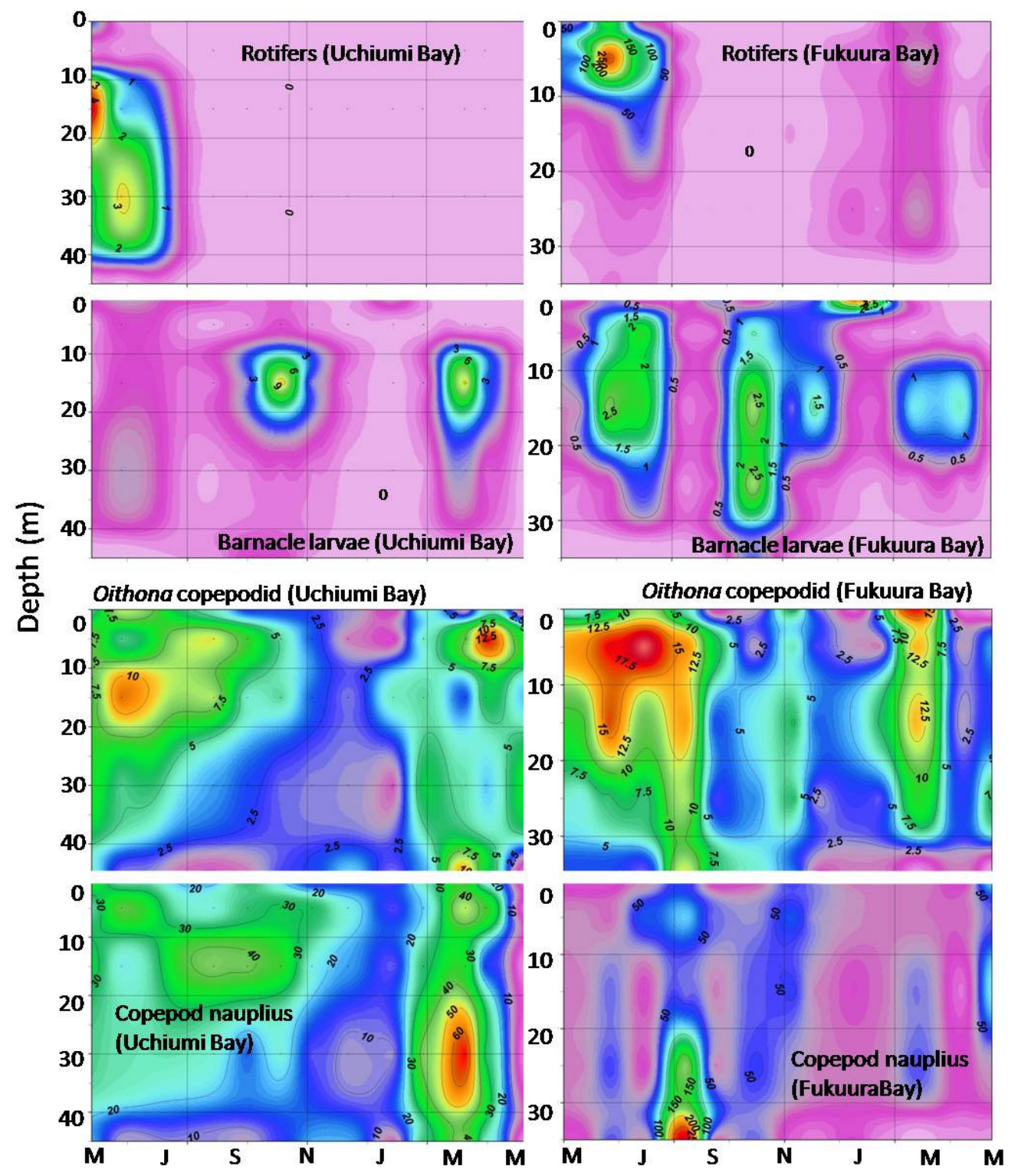

Fig. (6). Vertical distribution of microzooplankton (ind. $\mathrm{i}^{-1}$ ) at Uchiumi and Fukuura Bays during the study period (May 2005-May 2006).

food is metabolized by fish and excreted into the surrounding water as metabolic end products, e.g. carbon dioxide, urea and ammonia, and this affects the phytoplankton biomass [13, 14]. Higher ammonium and phosphate, but similar silica concentration might explain the difference in phytoplankton biomass of the bays, particularly temporarily higher nano-sized phytoplankton biomass in Fukuura Bay.

Despite higher phytoplankton biomass, zooplankton biomass of Fukuura Bay was markedly lower than that of Uchiumi Bay. Especially, larger sized species including Calanus showed marked difference in their biomass, while small cyclopoid, Oithona often showed higher biomass in Fukuura Bay. Although their occurrence was seasonally dependent, microzooplankton such as rotifer also showed higher abundances in Fukuura Bay. It has been reported that eutrophication often induces replacement of large copepods by small ones [9], and the relative proportion of microzooplankton including copepod nauplii and rotifers increases [15]. The changes in food availability by change of phytoplankton composition from microphytoplankters to pico-, and nanoflagellates are suggested as one important factor for the increase in the abundances of small species, since they are not able to feed diatoms. It can be thought that populations of Oithona and other microzooplankton have benefit from higher biomass of nano-sized phytoplankton in Fukuura Bay. The attached microalgae on the fish farming cage is also known as one important food source for Oithona spp [16].

At the same time, large calanoid copepod populations were strongly suppressed in Fukuura Bay. Unfortunately, we cannot precisely estimate the reason with our present data. However, one acceptable reason is the intensity of fish predation. Although it is difficult to estimate the relationship between eutrophication and fish population increase, it can be conceptually thought that eutrophication induces the increase of pelagic fish populations by increasing food supply [17]. Selective feeding behavior of pelagic fish, 
selecting larger prey, can increase the mortality rates of larger calanoid copepods such as Calanus, but not those of smaller Oithona [18], the body size of which is small enough not to be foraged. However, further study is required for better understanding the mechanism of top-down control of copepods in relation to eutrophication of coastal marine ecosystems.

Since mircozooplankton is not preferable food for fish and inefficient grazer on phytoplankton simultaneously, the efficiency of energy and material transfer in coastal food web can be lowered $[19,20]$. Increase of micro-sized zooplankton and small cyclopoids but low biomass and low diversity of calanoid copepods, observed in Fukuura indicates that fish farming can alter the structure and function of plankton community in coastal ecosystems. On the contrary, it has been reported that shellfish culture has relatively little impact on the environment [21], and our results also showed that less eutrophicated environments and different zooplankton community were observed in Uchiumi Bay.

In the present study, we briefly introduced our descriptive monitoring results from the two bays having different environments, one having fish farming effects and the other pearl oyster farming. It was clearly shown that fish farming has more serious impacts on water quality and overall alteration of zooplankton community. The results of this study also show that species composition and diversity of zooplankton community are reliable indicators of impacts of farming activities and eutrophication.

\section{ACKNOWLEDGMENTS}

We thank A. Kihara, I, Ninomiya, T. Yamamoto and M. Yoshihara for their supports in field monitoring. We are also grateful to the students of Laboratory of Aquatic Food Web Dynamics, Ehime University for their kind assistance during the sample collection and analyses. We also appreciate Dr. Takeoka H., Dr. Kaneda A., Dr. Fukumori K. and anonymous reviewer for their valuable comments. We also thank the staff members of Ainanchyo Institute of Oceanic and Fishery Science for their help in field sampling. This study was partly supported by Global COE program from the Ministry of Education, Culture, Sports, Science and Technology, Japan and the Japan Society for the Promotion of Science, and the Research Fund of coastal environment in Uchiumi Bay, Uchiumi Village, Ehime Prefecture.

\section{REFERENCES}

[1] Smith VH, Tilman GD, Nekola JC. Eutrophication: impacts of excess nutrient inputs on freshwater, marine, and terrestrial ecosystems. Environ Pollut 1999; 100:179-96.
[2] Yoshiyama K, Sharp JH. Phytoplankton responses to nutrient enrichment in an urbanized estuary: apparent inhibition of primary production by overeutrophciation. Limnol Oceanogr 2006; 51:42434.

[3] Nixon SW. Coastal marine eutrophication: a definition, social causes, and future concerns. Ophelia 1995; 41:199-219.

[4] Rosamond LN, Rebecca JG, Harold M, et al. Nature's subsidies to shrimp and salmon farming. Science 1998; 282:883-4.

[5] Yokoyama H. Impact of fish and pearl farming on the benthic environments in Gokasho Bay: evaluation from seasonal fluctuations of the macrobenthos. Fish Sci 2002; 68:258-68.

[6] Pitta P, Karakassis I, Tsapakis M, Zivanovic S. Natural vs mariculture induced variability in nutrients and plankton in the eastern Mediterranean. Hydrobiologia 1999; 391:181-94.

[7] Mazzola A, Sarà G. The effect of fish farming organic waste on food availability for bivalve mollusks (Gaeta Gulf, Central Tyrrhenian, MED): stable carbon isotopic analysis. Aquaculture 2001; 192:361-79.

[8] Pawar V, Matsuda O, Yamamoto T, Hashimoto T, Rajendaran N. Spatial and temporal variations of sediment quality in and around fish cage farms: a case study of aquaculture in the Seto Inland Sea, Japan. Fish Sci 2001; 67:619-27.

[9] Uye S. Replacement of large copepods by small ones with eutrophication of embayments: cause and consequence. Hydrobiologia 1994; 292/293:513-9.

[10] Uye S. Length-weight relationships of important zooplankton from the Inland Sea of Japan. J Oceanogr 1982; 38:149-58.

[11] Takeoka H, Koizumi Y, Kaneda A. Year-to-year variation of a Kyucho and a bottom intrusion in the Bungo Channel, Japan. In: Yanagi T, Ed. Interactions between estuaries, coastal seas and shelf seas. Tokyo, Terra Scientific Publishing 2000; pp. 197-215.

[12] Katano T, Kaneda A, Kanzaki N, et al. Distribution of prokaryotic picophytoplankton from Seto Inland Sea to the Kuroshio region, with special reference to 'Kyucho' events. Aquat Microb Ecol 2007; 46: 191-201.

[13] Tanaka Y. Decomposition process of pollutants. In: Japanese Society of Scientific Fisheries ed. Fish culture in coastal areas and self-pollution Senkai Yousyoku to Jika Osen Tokyo, KouseishaKouseikaku 1977; pp. 42-51.

[14] Sakami T, Abo K, Takayanagi K, Toda S. Effects of water mass exchange on bacterial communities in an aquaculture area during summer. Estuar Coast Shelf Sci 2003; 56:111-8.

[15] Park GS, Marshall HG. Estuarine relationships between zooplankton community structure and trophic gradients. J Plank Res 2000; 22:121-35.

[16] Doi $\mathrm{H}$, Chang $\mathrm{KH}$, Obayashi $\mathrm{Y}$, et al. Attached microalgae contribute to planktonic food webs in bays with fish and pearl farms. Mar Ecol Prog Ser 2008; 353:107-13.

[17] Caddy JF. Marine catchment basin effects versus impacts of fisheries on semi-enclosed seas. ICES J Mar Sci 2000; 57:628-40.

[18] Tor P, Nielsen TG, Tiselius P. Mortality rates of epipelagic copepods in the post-spring bloom period in Disko Bay, western Greenland. Mar Ecol Prog Ser 2008; 359:151-60.

[19] Olsen Y, Reinertsen H, Vadstein O, et al. Comparative analysis of food webs based on flow networks: effects of nutrient supply on structure and function of coastal plankton communities. Cont Shelf Res 2001; 21:2043-53.

[20] Sommer U, Stibor H, Katechakis A, Sommer F, Hansen T. Pelagic food web configurations at different levels of nutrient richness and their implications for the ratio fish production: primary production. Hydrobiologia 2002; 484:11-20.

[21] Crawford C. Environmental management of marine aquaculture in Tasmania, Ausralia. Aquaculture 2003; 226:129-38. 